\title{
ORDUÑA (BIZKAIA) Y VILLALBA DE LOSA (BURGOS): CONFLICTOS POR CUESTION DE LA PROPIEDAD FORESTAL DE SIERRA SALVADA
}

\author{
POR \\ Jesús maria garayo Urruela *
}

\begin{abstract}
SUMARIO: 1. INTRODUCCIÓN: 1.1 La Sierra Salvada; 1.2 Orduña y Villalba de Losa; 1.3 Relaciones comunitarias entre Orduña y Villalba de Losa.-2. LA PROPIEDAD forestal de SierRa Salvada BAJA: VISIÓN de CONJUNTO: 2.1 Uso silvopastoral $y$ propiedad compartidos de la Sierra Salvada (Ejecutoria de 1495); 2.2 Reparto a partes iguales de los ingresos recaudados por arrendamiento de pastos y prendarias de ganado (Concordias de 1645 y 1659); 2.3 División del arbolado (Convenio de 1798-Apeo 1847); 2.4 Comunidad en la propiedad y aprovechamientos del suelo (XIX y la mitad del XX); 2.5 Debates por la propiedad (1955-...).-3. PLEITOS Y DIFERENCIAS ENTRE ENTIDADES LOSINAS DERECHOHABIENTES O CONTRA DUEÑOS DE FINCAS COLINDANTES: 3.1 Aldeas de la tierra contra la villa de Villalba; 3.2 Villalba y Orduña contra entidades ajenas: 3.2.1 Llorengot; 3.2.2 Tierra de Ayala; 3.2.3 Cura de Múrita.-4. DISCUSIÓN POR EL ÁMBITO TERRITORIAL, OBJETO DE PROPIEDAD Y APROVECHAMIENTOS PRO INDIVISO. 5. Excepción de Sierra Salvada Baja de la desamortización e inclusión en el Católogo de Montes de UP. -6. Enfrentamiento frontal de Villalba de Losa con Orduña por la PROPIEDAd del mONTE "Dehesa del Agua».-7 Conclusiones.-Bibliografía.
\end{abstract}

\section{INTRODUCCION}

Históricamente, la propiedad sobre la tierra se ha iniciado, conservado y consolidado por medio de la costumbre, la ocupación y uso interrumpidos.

La disposición de títulos de propiedad por parte del dueño ha sido en épocas pretéritas e, incluso, actualmente lo sigue siendo, bastante raro y, en algunos casos, aquéllos no hacian sino legitimar documentalmente la conservación inmemorial en su poder de una determinada finca, pero no probaban de forma fehaciente los derechos dominicales del mismo sobre ella.

Las concesiones y donaciones reales o señoriales, las transmisiones hereditarias, las sentencias de los Tribunales, las concordias y transacciones amistosas, el tráfico comercial, los registros públicos, etc., han ido generando una serie de documentación, que ha ido supliendo un disfrute no-escriturado sobre el aprovechamiento de la tierra o, en último término, ha proporcionado elemen-

- Granja Modelo-CIMA. Apartado 46. 01080 Vitoria-Gasteiz.

Abreviaturas:

$\mathrm{AHMO}=$ Archivo Histórico Municipal de Orduña. Ayuntamiento de Orduña (Vizcaya) .

$\mathrm{AHPB}=$ Archivo Histórico Provincial de Burgos. Casa de Cultura. Burgos. 
tos para poder acceder a su inscripción en diferentes registros públicos.

La propiedad de la tierra encierra facultades relativas tanto al aprovechamiento y disfrute de los productos del terreno como a la disposición del mismo, abarcando la administración y gestión, la regulación técnico-productiva de los aprovechamientos, la defensa de uso abusivo por derecho-habientes o terceros, la comercialización de productos e, incluso, la venta de parte o de toda la finca, etc.

Tras el preámbulo anterior, que se considera interesante tenerlo en consideración para situar y comprender los problemas surgidos entre Orduña (Vizcaya) y Villalba de Losa (Burgos) por motivo de la propiedad y el uso en Sierra Salvada, se pasa a describir el monte, objeto de la disputa, y las partes en conflicto.

\subsection{La Sierra Salvada}

El macizo o Sierra de Salvada, situado entre 700 y 1.100 metros de altitud sobre el nivel del mar, comprende un dilatado territorio que, en sus extremos, surca las calzadas serpenteantes de los tradicionales accesos (Puertos de Orduña y Angulo), que unieron la costa vizcaína con la meseta castellana.

Jurisdiccionalmente, esta sierra pertenece a tres provincias distintas, Alava, Burgos y Vizcaya, confluyendo todas ellas en "Mojón Alto» o "Las Lastras».

Dominicalmente, el macizo se halla dividido en dos grandes porciones de terreno, siguiendo la divisoria de la línea trazada por los mojones de Las Lastras, Pozo Trevejo, Cueva Llana y Casco de la Peña.

La porción, situada al norte de esta línea, sobre los 1.000 metros de altitud, pertenece en su mayoria a los municipios alaveses integrantes de la Antigua Tierra de Ayala (Alava), y en una pequeña extensión Monte Iturrigorri, a la Junta de Ruzábal, aldeas de Orduña (Vizcaya).

El dominio de la otra porción, entre los 700 y los 1.000 metros de altitud sobre el mar, pertenece a Villalba que lo comparte con las aldeas de su tierra, estando en discusión los derechos que, en los referidos terrenos, corresponden a la ciudad de Orduña y sus aldeas de la Junta de Ruzábal.

A partir del siglo $X I X$, los términos, dehesas y montes comprendidos en la segunda porción, poseyeron un nombre específico. Entre los años veinte y treinta del XIX, la Tierra de Ayala exigió a Villalba que las moderadas multas, que experimentaban los ganados losinos al norte de la línea de mojones de Las Lastras, Pozo de Trevejo, Cueva Llana y Casco de la Peña, fuesen también de 
aplicación para los ganados ayaleses al sur de dicha línea. Villalba, para eludir la reciprocidad planteada por la Tierra de Ayala, utilizó entonces, para oponerse a sus reivindicaciones, en base a las diferencias de altitud el nombre de Sierra Salvada "Baja» en cuanto designaba una porción de términos, dehesas y montes, distintos a los llamados Sierra Salvada "Alta», perteneciente a Ayala.

Este nombre sustituye en la documentación del XIX a los de Sierra Salvada y a los de las tres dehesas de Anzalón, del Agua y de los Valles, miméticamente repetidos en la documentación los siglos $X V$ y XVIII, desde el cual, tras el reparto de arbolado, pierden su significación y el valor identificativo.

En las gestiones realizadas conjuntamente por Villalba y Orduña para excluir a los montes de la Sierra de las ventas desamortizadoras, se les integra a todos ellos en la denominación Sierra Salvada Baja. Sin embargo, en la inscripción en el Catálogo Provincial de Burgos de Montes de Utilidad Pública, como consecuencia de ser exceptuados de la desamortización, no se registraron estos montes como Sierra Salvada Baja sino que se subdividieron en tres montes distintos con asignación de pertenencias diferentes: dehesa de Anzalón (núm. 443) a los pueblos de Villalba y Múrita, los Valles (núm. 452), al pueblo de Villalba de Losa, y Dehesa del Agua (núm. 447), al pueblo de Villalba y otros, a saber, Múrita, Mijala, Zaballa y Orduña.

En el primer tercio del siglo $\mathrm{XX}$, ambas entidades seguían utilizando conjuntamente el nombre de Sierra Salvada Baja. La Ordenación de los aprovechamientos, establecida para estos montes en los años cuarenta por la administración forestal, fue el momento, en el que las denominaciones de los montes, registradas en el Catálogo, iniciaron su creciente y definitiva implantación. EI nombre de Sierra Salvada Baja fue objeto de polémica al final de los años cincuenta, negándole Villalba validez alguna y defendiendo Orduña lo contrario al ser un vocablo, que refleja el ámbito territorial de los diferentes derechos poseídos por Orduña en la Sierra.

\subsection{Orduña y Villalba de Losa}

Los pueblos con derechos sobre la propiedad, el uso y los aprovechamientos en Sierra Salvada Baja se integran en dos entidades administrativas y socialmente diferenciadas: la villa $y$ tierra de Villalba de Losa y la ciudad y tierra de Orduña (1).

(1) Para estudiar la trayectoria histórica de las dos partes participantes en Sierra Salvada Baja puede consultarse diversa bibliografia. En el caso de la ciudad y tierra de Orduña, resulta útil la lectura de J. E. URIARTE. M. SARASOla (1957), J. R. MADARIA (1971 y 1981), J. MARIA URRUELA (1977) y J. L. ORELLA UNZÚE (1980). En cuanto a Villalba de Losa, el autor a manejar es J. GARCIA SAINZ DE BARANDA (1947-1949), que puede completarse con trabajos breves pero 
La ciudad de Orduña y su tierra, compuesta de cuatro aldeas, Belandia, Mendeica, Lendoño de Arriba y Lendoño de Abajo, agrupadas en la Junta de Ruzábal, lindan por el este con la Sierra Salvada tanto en su porción alta como baja.

En la parte occidental de la Sierra, a 666 metros de altitud, se encuentra Villalba de Losa con sus aldeas anejas de Múrita, Mijala y Zaballa.

La Sierra Salvada es el espacio geográfico que separa a Orduña de Villalba de Losa. Orduña, situada al pie del murallón, que la limita en su parte oriental, tiene mayores dificultades, aunque salvables, de acceso a la sierra que Villalba, ubicada en el extremo suroccidental, sobre las pendientes más suaves de la meseta que presenta la sierra.

\subsection{Relaciones comunitarias entre Orduña y Villalba de Losa}

Villalba y su tierra, es decir, Múrita, Mijala y Zaballa, pueblos rurales, que no han llegado a superar el techo histórico de los 500 residentes, en sus enfrentamientos con Orduña relacionados con Sierra Salvada Baja, han desarrollado más posturas de choque y hostigamiento que de renuncia y concordia.

Orduña, confiada en sus derechos en la Sierra y en los resortes, que con su poder económico y político, podía movilizar para hacerlos valer si fuera preciso (2), se ha comportado con Villalba con formas más distendidas, dándose casos de condonación en aspectos que, inexplicablemente, le correspondían, si, con ello, cesaban las diferencias.

Villalba, dada la desigualdad de partida en medios humanos y económicos, ha mostrado un recelo histórico por la presencia en la Sierra de la poderosa ciudad vecina y, quizá, esta posición de debilidad que, en ocasiones, le facilitó el desempeñar el papel de

monográficos sobre la villa (J. CADIÑANOS, 1984) o con publicaciones de ámbito comarcal, apoyadas en profundas investigaciones locales (J. ORTEGA VALCÁRCEL, 1974).

En base a los datos facilitados por N. RODRiGUEZ MORO, entre una serie de montes, que se caracterizaban por reunir los rasgos de las comunidades de tierra, A. NIETO (1964, 339), dentro de la provincia de Vizcaya incluyó los montes que integran la comunidad, a la que los dos autores referidos denominan Sierra Salvada Baja. Estos montes, sin embargo, están ubicados en la provincia de Burgos y no son una comunidad de tierra sino la comunidad de montes formada por dos entes, que cada uno por separado se configuraban como villa $y$ tierra.

(2) El uso que Orduña hacia de las relaciones e influencias que le proporcionaba su poderio económico y político quedó patente en la correspondencia que mantuvo con el procurador en el pleito sobre jurisdicción hacia 1745. Así, en la carta enviada el 17 de agosto le manifestaba la conveniencia de conocer el nombre de los jueces, a los que correspondía juzgar el asunto con el fin de poder "pasar alguna recomendación». En la carta de 11 de septiembre de 1745, Orduña insistió en el tema, pero esta vez trataba de llegar a los jueces a través de la Diputación del Señorio de Vizcaya, que se había solidarizado con la ciudad: «Supongo habrá Vd. usado de el poder que este M.N.Señorío dió mostrandose parte a favor de la ciudad y jurisdicción de ellos pues yo quisiera hacer un recuerdo a la Diputación para que se interesare en facilitar empeños dirigidos a conseguir la gracia de esos señores)) (AHMO, Sentencias, 2) 
víctima (3), le ha mantenido siempre alerta ante los comportamientos de Orduña que, en algún caso, como el relativo a la jurisdicción. tal como se demostró ante los Tribunales, atentó contra los derechos de la villa y tierra burgalesas.

En la historia del monte, ha habido momentos de gran tensión intercomunitaria, llegando a las riñas e, incidentes armados. Los años finales del $X V$, en los que se discutió numerosos aspectos de la sierra, los debates sobre jurisdicción (setenta del XVI, primer decenio del XVII Y cuarenta del XVIII, los aprovechamientos del vuelo a fines del XVIII $y$ los períodos del $X X$, en donde vuelve en cierto modo a cuestionarse como, en el XV, toda la situación de la sierra, corresponde a épocas de agudos conflictos.

En contraste, también, sucedieron largos períodos de tiempo, en los que predominó un uso conjunto de la sierra sino, en total armonía -debates siempre ha habido-, si en pacífica convivencia. Así, prácticamente el siglo XIX completo y el primer tercio del siglo $X X$, pasaron $\sin$ apenas cuestiones de entidad.

\section{LA PROPIEDAD FORESTAL DE SIERRA SALVADA BAJA: VISION DE CONJUNTO}

Las relaciones, entre Villalba y sus aldeas con Orduña y la Junta de Ruzábal, han sido objeto de múltiples disputas y diferencias, que han generado una abundante documentación de valor y significado legales divergentes. En lo que respecta a la propiedad de Sierra Salvada Baja, la documentación a tener en cuenta son la Carta Ejecutoria de 22 de mayo de 1494, las Concordias de 5 de julio de

(3) Villalba, en el proceso legal que sostuvo con Orduña a finales del XV. aparentó el papel de víctima intentando vanamente en hacer creer a los jueces que la presencia de Orduña en la sierra se debía a una posición de fuerza, ligada a su poderio económico y político: «... si algunas veces o en algunos tiempos las dichas partes adversas habían entrado con sus ganados o sin ellos a pacer y rozar o cortar en la dicha sierra aquello habría sido a hurto y escondidamente no lo supiendo las dichas partes y que si lo habrian sabido aquellos habría sido y sería por fuerza y contra voluntad de las dichas sus partes por ser como era la dicha ciudad y su tierra más poderosa y de más gente y de más vecindad que la dicha villa de Villalba y su tierra pero no porque las dichas partes adversas hubiesen tenido y tuviesen derecho costumbre ni posesión de pacer en los dichos términos...) (AHMO. Sierra Salvada, 21 y 22). La desigualdad en población, en poder económico y politico, en relaciones e influencias, etc.. fue nuevamente resaltado por Villalba en la querella que en fecha de 25 de junio de 1694 puso contra Orduña por el asunto de la venta de Goldecho: la ciudad de Orduña posee «... muchos propios y rentas vecinos $y$ personas $y$ acaudalados y de mucha mano y poder en los tribunales $y$ al contrario de dicha villa y su tierra componerse de muy corta vecindad pocos caudales ni más industria que una tenue labranza y alguna crianza de ganados y de que si se da lugar a que dicha ciudad fabrique dicha venta y se apodere de dicha Sierra se han de causar considerables fraudes en los géneros de vino, aceite y vinagre por lo que suplico mande recibir dicha información al tenor de lo referido y fecháseme de un traslado dos o más para los efectos que cunvengan interponiendo su autoridad y decreto en forma es justicia que pido..." (A. Ch. V., Pleitos de Vizcaya, Leg. 1.200/4).

REVISTA DE ESTLDIOS. $-\gamma$ 
1645 y de 4 de diciembre de 1659, y el Convenio de 19 de septiembre de 1798 sobre división del arbolado. A lo anterior, como información complementaria, se suma una variopinta documentación compuesta de apeos, requisitorias y querellas legales, expedientes, actas municipales, dictámenes legales, a los que se ha acudido en la medida que tienen relación con el tema de la propiedad en Sierra Salvada Baja.

\subsection{Uso silvopastoral y propiedad compartidos de la Sierra Salvada (Ejecutoria de 1495)}

Documentalmente, se conoce la existencia de Orduña y Villalba como núcleos de población desde la Alta Edad Media: Orduña desde finales del siglo $x$ y Villalba para el XI.

El disfrute de los aprovechamientos de la sierra, particularmente de los pastos de verano, por los vecinos de ambas, resulta una hipótesis bastante clara si se tiene en cuenta que los montes de la divisoria de la vertiente cantábrica con la meseta castellana, entre los que se incluía la Sierra Salvada en su extremo más oriental, en la etapa altomedieval, se caracterizaba por constituir un espacio de pastoreo indiferenciado y común para todos los concejos ubicados en su proximidad (J. Ortega Valcárcel, 1974).

Para los inicios del XV, consta que Villalba y Orduña sostuvieron diversos enfrentamientos por los aprovechamientos en Sierra Salvada, zanjados amistosamente por la firma de una concordia, fórmula elegida para conciliar los derechos que una y otra parte defendian tener sobre dominio, posesión y aprovechamiento de la sierra.

En la década final del $X V$, las diferencias y los debates renacieron y ambas partes mantuvieron un pleito en el que, junto a diversas cuestiones, lo que se trataba era la pertenencia de Sierra Salvada: Villalba trataba de conseguir de los Tribunales el reconocimiento como su único y exclusivo propietario, mientras Orduña defendía la propiedad común de la misma.

Orduña justificó sus derechos en Sierra Salvada con la presentación de pruebas documentales, en la actualidad perdidas. En concreto, se hacía referencia a un privilegio o real, probablemente, concedido por Sancho IV, en el que Orduña había obtenido ciertas concesiones sobre la posesión y aprovechamientos en la Sierra, y a la Concordia mencionada, a partir de las cuales Orduña argumentó estar presente en Sierra Salvada desde tiempo inmemorial (4).

La defensa legal de Villalba, centrada en declaraciones de testigos, trataba de demostrar que la Sierra Salvada caía dentro de

(4) AHMO, Sierra Salvada, 21 × 22. 
su jurisdicción, que toda ella formaba una dehesa o zona acotada para los aprovechamientos, cuyo acceso, en ciertas épocas, quedaba íncluso vedado a sus propios vecinos y que, repetidas y numerosas veces, había obtenido de Orduña contraprestaciones monetarias o rentas por aprovechamiento en la misma (5).

Cada una de las partes procuró resaltar los puntos «débiles» de la contraria. Orduña aludió a la escasez de pruebas documentales y a su escasa consistencia por no estar debidamente legalizadas (6). Villalba, en cambio, resaltó el bajo número de testigos presentados en relación a un uso inmemorial y continuado, que Orduña pretendía probar (7).

Intentando por todos los medios el realce de sus propias posiciones y argumentos, cada parte procuraba limar los puntos consistentes y fuertes de la otra y, de este modo, relativizar, en lo factible, su valor. Ante la incuestionabilidad del privilegio poseído por Orduña, Villalba orientó su defensa en la dirección de demostrar la posesión de títulos documentados que amparaban su presencia en Sierra Salvada (8). Diferente estrategia desarrolló respecto a la Concordia, a la que negó existencia y, en el caso de que así lo fuera, no lo reconoció, alegando falta de legitimidad en la extensión y firma del documento (9). Por su parte, Orduña relativizó lo afirmado por los testigos, resaltando el carácter de parcionero, que los lugares, en donde los testigos residian, mantenía con Villalba.

Según el contenido de la sentencia definitiva, la Sierra Salvada estaba dividida en zonas acotadas y reservadas a Villalba y otras comuneras de ésta con Orduña en el disfrute de los aprovechamientos, tanto del suelo como del vuelo:

- En la dehesa de Anzalón, los aprovechamientos de corta, roza, pastos y aguas, correspondían exclusivamente a Villalba de Losa y aldeas.

- En las dehesas del Monte Redondo y Lago de San Juan, Villalba era el titular privativo de los aprovechamientos del vuelo $y$, en el suelo, de la roza. La titularidad del resto de los aprovechamientos del suelo (aguas, pastos, etc.) la compartía con Orduña.

- En el resto de los términos no apeados, la titularidad de los aprovechamientos tanto de suelo como de vuelo era compartida entre Villalba y Orduña.

- En base a lo anterior, exceptuando la dehesa de Anzalón, pastos y aguas eran detentados por una co-titularidad integrada por las partes litigantes.

(5) AHMO, Sierra Salvada, 21 y 22

(6) AHMO, Sierra Salvada, 21 y 22.

(7) AHMO, Sierra Salvada, 21 y 22.

(8) AHMO, Sierra Salvada, 21 y 22.

(9) AHMO, Sierra Salvada, 21 y 22. 
La sentencia del 8 de octubre de 1493 estableció una comunidad prodivisa, en Monteredondo y San Juan, dehesas en las que los diferentes aprovechamientos eran detentados por sujetos distintos (madera y roza para Villalba y aldeas y pastos, aguas y demás aprovechamientos del suelo para Villalba y aldeas además de Orduña con su tierra), mientras que, en el resto de términos, al ser comuneros tanto los aprovechamientos del suelo como del vuelo, implantó una comunidad pro-indivisa.

La sentencia definitiva determinó a quién correspondían la titularidad de los aprovechamientos, según fuesen privativos o comuneros, pero, de forma expresa, no se pronunció sobre la propiedad y dominio del conjunto de la sierra, es decir, sobre Anzalón, Monte Redondo y Lago de San Juan además de los demás términos comuneros. Sin embargo, si se tiene en cuenta lo reclamado por Villalba, es decir, el dominio privativo de la sierra y el contenido de la sentencia definitiva, es preciso concluir con las rnotivaciones y excepciones contenidas en la misma, en una confirmación de los derechos de Orduña en la Sierra tanto en los aprovechamientos como en el dominio. Así venía a reconocerse en la sentencia de vista, que utilizó la palabra posesión para amparar así a Orduña en el disfrute de la sierra en cuanto a los aprovechamientos de madera y pastos, con la exclusión de las dehesas de Anzalón, Monte Redondo y Lago de San Juan, que, por sentencia definitiva, quedaron reducidos a la dehesa de Anzalón (10).

Para acallar futuros conflictos, la sentencia definitiva incluía un párrafo final, por el que venía a decir que la exacta y verdadera interpretación del texto del privilegio poseído por Orduña respecto a Sierra Salvada era la que quedaba reflejada en las declaraciones, en ella contenidas (11). Al haber desaparecido el documento, la inclusión de su contenido, como de otros, que se citan, y actualmente se han perdido, además de su valor histórico, hubiera reportado para Orduña la posibilidad de sustentar sus derechos en la sierra en títulos fehacientes e indiscutibles (12). En cualquier caso, la ejecutoria de 1494 dejó probada su existencia así como nos ha transmitido la correcta interpretación del mismo, lo que basta para probar los derechos de Orduña en la sierra.

(10) AHMO, Sierra Salvada, 21 y 22.

(11) AHMO, Sierra Salvada, 21 y 22.

(12) AHMO, Pleitos y Sentencias, 3, 14. 


\subsection{Reparto a partes iguales de los ingresos recaudados por arrendamiento de pastos y prendarias de ganado (Con- cordias de 1645 y 1659)}

La cuestión de la propiedad en los terrenos comprendidos en Sierra Salvada Baja, con exclusion de la dehesa de Anzalón, no volvió a renacer hasta mediados del XVII. Por esas fechas, Villalba y Orduña discutieron por el arrendamiento de los aprovechamientos y ejecución de prendarias en los terrenos que, por la ejecutoria de 1494, habían quedado como comuneros tanto para gastos como para aprovechamientos forestales. Villalba negaba a Orduña capacidad de disposición sobre el monte en materia de arrendamiento y ejecución de prendarias con lo que venía a defender sobre los terrenos "comuneros» de la Ejecutoria de 1494 la existencia de una comunidad, no proindivisa, sino prodivisa, pues Villalba decía poseer facultades sobre el monte que, sin embargo, negaba que pudieran corresponderle a Orduña.

Las Concordias de 1645 y 1659 tanto en el tema del arrendamiento como en el de las prendarias concedieron idénticas facultades a cada una de las partes. Ninguna podía proceder a arrendar aprovechamientos sin aviso y consentimiento de la otra y los beneficios económicos debian repartirse a partes iguales. Las Concordias otorgaron a ambas entidades la facultad de ejecutar prendarias, siendo preceptivo, transcurrido el plazo de veinticuatro horas, el aviso de su realización por la parte ejecutante que, además, estaba obligada a hacer entrega a la otra de la mitad, deducidos costos, de los ingresos recaudados por este concepto. En fin, las Concordias de 1645 y 1659 establecieron una comunidad e igualdad por ambas partes en el disfrute de los pastos de Sierra Salvada Baja sin más exclusión para Orduña que la Dehesa de Anzalón con las peculiaridades que la ejecutoria de 1494 contempla para las callejas de "Zurruciaga».

En contraste con sentencias y concordias, que determinaban los aprovechamientos de la sierra, excluidos los forestales en las dehesas, como "comuneros», "comunes» o "es común en igualdad», según decía la Concordia de 1659, se encuentran apeos, así el de 4 de diciembre de 1716 , en los que se habla de visitar los mojones de alcance o alcances que Orduña poseía en Sierra Salvada. Orduña, sin embargo, basaba sus derechos a los aprovechamientos en la sierra, no en alcances o servidumbres, sino en una comunidad en la posesión y disfrute de los aprovechamientos, derivados y sancionados por privilegio real (13).

(13) AHMO, Pleitos y Sentencias, 3, 14. 
La documentación disponible sobre los siglos XVII y XVIII, al reflejar diferencias y debates intercomunitarios en las zonas comuneras, aclara diversos términos y montes de aprovechamiento común: en los pastos, lo eran Monte Redondo, Pozos de Ongoño, Valles de Arroje, Dehesa del Lago, Valle del Hayal y el Pozo de La Lastra. Mancomunidad de aprovechamientos maderables existía en el Valle de las Callejas, Hayal de Ongoño, Valle de Arroje y Valle del Hayal.

\subsection{División del arbolado (Convenio de 1798-Apeo 1847)}

El convenio de 19 de septiembre de 1798 sentó las bases de la disolución de la comunidad de arbolado establecida en la Ejecutoria de 1494 en aquellos términos de Sierra Salvada no comprendidos en las dehesas de Anzalón, de Monte Redondo y del Lago de San Juan. El Convenio de 19 de septiembre de 1798, materializado por el apeo de 28 de octubre de 1847, simplificó el aprovechamiento maderable de la sierra, asignándose a Orduña el arbolado de Garduña, Recuenco, Ongoño y Valle de Lechega, en el área del monte, próxima al casco y situado entre las Peñas de Goldecho y San Bartolomé, correspondiendo el resto a Villalba y sus aldeas.

\subsection{Comunidad en la propiedad $y$ aprovechamientos del suelo ( $X I X, y$ mitad del $X X)$}

Para el siglo $X I X$ y primer tercio del $X X Y$, también, aunque más aislados, para el XVII y el XVIII, se poseen un conjunto de hechos relativos a la administración y gestión de la sierra, defensa contra usos intrusivos de terceros, en los que Orduña y Villalba actuaron de común acuerdo, yendo en gastos como en repartos de beneficios, por mitad, como es el caso de las prendarias, de la construcción, conservación y limpieza de pozos, del cerramiento de cuevas y portillos, de los aprovechamientos de boñigas, etc.

Villalba y Orduña, también, intervinieron conjuntamente en los dos hechos sucedidos en el XIX y relacionados con terceros: pleito con la Tierra de Ayala por multa de prendarias y excepción de la finca de la desamortización promulgada por el Estado.

La comunidad en los aprovechamientos de Sierra Salvada entre Orduña y Villalba no fue un tema en discusión a lo largo del siglo $X I X$, al menos, en los diccionarios de la época, como el de Madoz, en el que, en el artículo dedicado a Orduña se puede leer: «... la Sierra Salvada, comunera con el valle de Losa, tiene buenos pastos en verano» (J. Madoz, 1849, XII, 30). 


\subsection{Debate por la propiedad (1955-...)}

El replanteamiento de la propiedad de la sierra sucedió en los años cincuenta del $x X, y$ siguientes, siendo el factor desencadenante las subastas de pastos. Estas, introducidas en la gestión del monte por exigirlo la administración forestal, arrancaron con problemas en 1945, pero resueltos al no tener Orduña inconveniente en compartir con Villalba, Múrita, Mijala y Zaballa, los pastos de la Dehesa de Agua, que había adquirido mediante el ejercicio del derecho de retracto, se sucedieron en 1946 y en 1951, sin incidentes importantes, con la intervención conjunta y desembolso a partes iguales de los gastos ocasionados por la obtención de las licencias de pastos (14).

La celebración de la subasta de 1955 en la que Villalba negó a Orduña la participación en la misma, puso de manifiesto las consecuencias que tenía la cumplimentación poco rigurosa, con que se llevó a cabo la inscripción del predio en el Catálogo de Montes a principios del XX. Así, Villalba, Múrita, Mijalda y Zaballa, sirviéndose de que, en la inclusión en el Catálogo de Montes de Utilidad Pública de la Provincia de Burgos (1901), dentro de la casilla de pertenencia de los tres montes, en los que se subdividió la sierra, es decir, Anzalón, los Valles y la Dehesa del Agua, no figuraba Orduña específicamente sino de forma global bajo el vocablo "otros» en el núm. 447, y amparándose en la legislación forestal acerca de la asignación de propiedad en montes de utilidad pública, negaron al ayuntamiento vizcaíno participación o derecho alguno en la sierra.

En esta época, aunque los debates por la subasta de pastos se concentraron primordialmente en el monte la Dehesa del Agua, las reivindicaciones por el condominio en la propiedad y uso de los aprovechamientos del suelo se ampliaron también al monte "Los Valles», incluidos en el Catálogo Provincial con el número 452. Los Valles eran un monte comunero al menos en los aprovechamientos tal como aparece en la Concordia de 1659 y en el apeo de 6 de noviembre de 1669 (15). Con el reparto de arbolado según Convenio de 1798, la comunidad quedó reducida a los pastos. Orduña no dejó de protestar, como puede verse por el acta de 11 de enero de 1846, cuando, habiendo mantenido Villalba una reunión con otros pueblos de Losa sobre pertenencia y derechos en el término de Arroje, no se le citó a la reunión, previniéndole de que

(14) AHMO, Sierra Salvada, 30.

(15) AHMO, Sierra Salvada, 2 y 27 , y Apeos Villalba, 22. 
nada perjudicial a sus intereses pudiese derivarse de lo mismo (16).

Con la inscripción en el Catálogo de Montes de Utilidad Pública, con el número 452 y bajo la denominacion de Los Valles, la situación no varió, como lo reconoció el mismo Villalba por oficio de 20 de diciembre de 1926, por el que se solicitaba la mitad de los gastos causados por la expedición de la licencia de aprovechamiento de pastos tanto en el monte Los Valles como en la Dehesa del Agua (17). Villalba, al rechazar en los años cincuenta de este siglo los derechos dominicales de Orduña en Dehesa del Agua, a la vez, lo hizo para el monte "Los Valles» ya que el acceso al monte por parte de Orduña discurre a través del primero.

Cuando se levantó el Catastro parcelario de las fincas rústicas del municipio de la Junta de Villalba de Losa, las actas de los polígonos, en los que están incluidas las diferentes parcelas de los tres montes mencionados, lleva fecha de 11 de noviembre de 1957, la asignación de pertenencias para Anzalón y los Valles coinciden con las del Catálogo de Montes de Utilidad Pública, Villalba y Múrita, para el primero y Villalba, para el segundo mientras que, en relación a la Dehesa del Agua, además de Villalba, se incluyeron los pueblos de Múrita, Mijala y Zaballa sin hacer referencia alguna al Ayuntamiento de Orduña (18).

La obligación de inscripción en el Registro de la Propiedad que la legislación marca para los montes de Utilidad Pública, se efectuó en el caso de los Valles, con fecha de 8 de marzo de 1965, número de finca 4.234, página 55 del tomo 1.242 del Registro de Propiedad del Partido Judicial de Villarcayo. El registro se hizo, tal como consta en el Catálogo de Montes de Utilidad Pública, a favor de Villalba de Losa (19).

(16) AHMO. Acta de la sesión celebrada por el Ayuntamiento

(17) AHMO, Sierra Salvada, 30.

(18) El pago de la contribución fue uno de los argumentos manejados por el presidente de la Junta Administrativa de Villalba de Losa para demostrar su dominio sobre la finca $y$, de este modo, rechazar la entrega de documentos de reclamación contra la subasta de pastos de 1955 que Orduña pretendía llevar a cabo a través del notario de Quincoces. Orduña llegó a pagar la mitad de la contribución rústica correspondiente a la Dehesa del Agua para el año 1952 sin que se conozcan más referencias sobre este punto para otros años. En cualquier caso, el Catastro de Riqueza Rústica es un Registro Público con fines fiscales. Para tener efectos probatorios en el campo de la propiedad será preciso añadirle unas garantias de exactitud y precisión jurídicas que en la actualidad no posee.

(19) El Registro de la Propiedad de Villarcayo, en la página 55 del tomo 1.242 y con el número de finca 4.234, consta, como primera y única inscripción. lo siguiente: «Rústica un monte en término municipal de Villalba de Losa, denominado "Valles", que linda: Norte, sierra calva; este, camino de Peña Vieja; sur, propiedad particular, y oeste, con pared y sierra. Su cabida es de cincuenta $y$ ocho hectáreas. No constan cargas ni su valor. Señalado con el número 452 en el Catálogo de montes de Utilidad Pública de Burgos, en el cual se asigna al pueblo de Villalba de Losa, sin que exista plano topográfico, ni esté deslindado, ni existan antecedentes 
Las anotaciones del Registro de la Propiedad, para los Valles, y del Catastro de Riqueza Rústica, para el monte de la Dehesa del Agua, constituyen un episodio más en el proceso de apropiación de la sierra por parte de Villalba de Losa y sus aldeas, proceso secular, en el que se han sucedido períodos de reconocimiento con los de rechazo de la presencia orduñesa en Sierra Salvada.

\section{PLEITOS Y DIFERENCIAS ENTRE ENTIDADES LOSINAS DERE- CHOHABIENTES O CONTRA DUEÑOS DE FINCAS COLINDANTES}

Los derechos que asisten a Orduña en Sierra Salvada Baja, han sido reconocidos por las entidades con las que comparte la propiedad y el uso, cuando, conjuntamente, aliados ciudad y tierra y villa con aldeas, pleitean con entidades ajenas al predio objeto de disfrute 0 , también, cuando surgen diferencias internas por los aprovechamientos entre villa y aldeas de su tierra y éstas acuden a la ciudad.

\subsection{Aldeas de la tierra contra la villa de Villalba}

Villalba, con su tierra, no sólo desarrolló una estrategia de hostigamiento respecto a Orduña y sus aldeas, al fin y al cabo, una entidad distinta y un molesto compañero en cuanto al dominio, uso y gestión del monte, sino que también trasladó el campo de las diferencias al propio seno de su unidad institucional, compuesta de dos partes diferenciadas, villa y tierra, entre las que los conflictos, por unos o por otros motivos, tampoco podian faltar.

Hacia 1699, Villalba prendó y multó a vecinos de Mijala y Zaballa, negándoles el derecho a los pastos, cortas, rozas y demás aprovechamientos. En estas circunstancias, Juan de Lapresa, cura

de titulo de propiedad, estando destinado al servicio de monte. En su virtud inscribo el dominio de esta finca a favor del pueblo de Villalba de Losa según el artículo 206 de la Ley Hipotecaria, sin efectos respecto de terceros durante dos años y siendo cancelada la inscripción si no se acredita la publicación del edicto. Así resulta de Certificación por cuadruplicado expedida en Burgos el veinte de octubre del pasado año, por Don Antonio María Giménez Rico, Jefe del Distrito Forestal, que se ha presentado a las once horas del día cinco del pasado mes de Febrero, asiento 195 folio 35 vuelto diario 48, quedando archivado uno de los ejemplares. Exento del impuesto. Villarcayo a ocho de marzo de mil novecientos sesenta y cinco. Fdo. ilegible. El edicto referente a la inscripción fue publicado durante un mes en el ayuntamiento, en donde radica la finca, en la forma reglamentaria por certificación presentada por el secretario del Ayuntamiento de Villalba de Losa, según consta en anotación al margen de la inscripción referida con fecha 7 de junio de 1965".

Al municipio de Orduña, ni el Distrito Forestal, que de sobra conocia el conflicto que mantenía el Ayuntamiento vizcaino con Villalba de Losa, Múrita, Mijala y Zaballa, y no se le pudo pasar por alto las pretensiones de Orduña en relación a los Valles, ni el Registro de la Propiedad de Villarcayo, le enviaron por este motivo notificación alguna para que pudiera hacer valer sus derechos. 
de Mijala, en representacion de las partes agraviadas, con fecha de 2 de noviembre de 1669, dirigió al Ayuntamiento de Orduña un escrito, en el que le avisaban de la realización de las prendarias sin conocimiento ni entrega de la mitad correspondiente a Orduña y por el que le solicitaba la entrega, previo pago de los derechos pertinentes, de un traslado fehaciente de la Real Carta Ejecutoria de $1494 \mathrm{y}$, en último término, la intercesión ante la villa de Villalba, previniéndole de lo injusto de su proceder (20). La intervención de Orduña hubo de ser positiva a la hora de convencer a Villalba de lo improcedente de su comportamiento ya que nada se conoce al respecto.

En los inicios del siglo XIX. Múrita, Mijala y Zaballa se vieron impedidos por la villa de Villalba en el disfrute de los aprovechamientos maderables en las dehesas de Anzalón, Monte Redondo y San Juan del Lago con la majada de Golortiza. El asunto trascendió a los tribunales $y$, en el marco del reconocimiento y medida de los términos en disputa, solicitado por Villalba, Manuel Prieto, procurador de las aldeas pidió y obtuvo Real Provisión, por la que, como parte interesada, se citaba a Orduña y ordenaba su presencia en el señalado reconocimiento de términos (21). El reconocimiento todavía a finales del año de 1806 (22), no se había llevado a cabo $y$ es probable que no se efectuase, pues, de haber sucedido, Orduña obligatoriamente habria de haber asistido y tenía que haber quedado constancia documental, que no existe.

Estos dos casos, a los que pueden sumarse las intervenciones de abogados en nómina municipal del Ayuntamiento de Orduña, como la de Ventura Ortiz de Zárate en la firma de la Concordia de 1659 (23) o la de Juan Bautista Leal de Ibarra, como juez árbitro de diferencias tenidas en 1802 entre Villalba y Junta de Estrada (24), convertían a Orduña o a vecinos de la misma en instancia arbitral y de mediación, ligadas no solamente a la participación en el uso y posesión de Sierra Salvada Baja, sino, también, por sus rasgos de centro económico y comercial de un espacio comarcado, en el que se integraba Losa, y del contacto social y relaciones que, a partir de ello, se derivaban.

\subsection{Villalba y Orduña contra entidades ajenas}

Las diferencias tenidas por Orduña y Villalba sobre aprovechamientos en Sierra Salvada Baja con entidades dueñas de fincas

(20) AHMO, Pleitos y Sentencias, 2, 1

(21) Real Provisión, Valladolid, 8 de mayo de 1805, escribano Castro Taboada (A. Ch. V., Registro de Reales Provisiones, 747)

(22) AHMO, Sierra Salvada, 10.

(23) AHMO, Sierra Salvada, 24.

(24) AHMO, Pleitos y Sentencias, 3, 14. 
colindantes se reducen a las habidas con Llorengot, la tierra de Ayala y el cura de Múrita.

\subsubsection{Llorengot}

Las ferias y mercados constituian una oportunidad para renovar el capital ganadero de la explotación. En las ferias y mercados de Orduña, esta renovación se conseguiría por medio de bueyes asturianos. En su camino hacia la ciudad, estos ganados, provenientes de Mena y atravesando la Sierra Salvada Alta, solian detenerse en Llorengot, último lugar antes de llegar a Orduña, en cuyos términos pastaban, esperando la celebración de las ferias y mercados orduñeses.

A partir de la segunda mitad del siglo XVII si se llegó a celebrar se aprovechaba el paso y detención comentados para operaciones de compra-venta por un montante importante. En 1656 se habla de trescientos bueyes, que por los perjuicios ocasionados provocó la actuación judicial de Orduña contra Llorengot, de lo que se tiene constancia en 1668 y 1689 (25).

A partir de la conculcación de los intereses comerciales, Orduña con Villalba se veían perjudicados por un aprovechamiento fraudulento de los pastos de Sierra Salvada Alta. Llorengot alquilaba los pastos a los asturianos, pero el número de ganados forasteros era tal que desequilibraba la relación entre cabaña pastante y recursos pastables y obligaba a Llorengot a usar de la picaresca y mantener los ganados de dia dentro de sus términos "barreras adentro», para de noche trasladarlos de "barreras afuera», a la finca y términos en jurisdicción privativa de Villalba y con aprovechamiento de pastos compartidos por villa y ciudad (26).

Este desequilibrio entre recursos pastables y efectivo ganaderos volvió a reproducirse con ocasión del arrendamiento de pastos, en 1675, a Francisco de La Rasa, encargado de abastecer de carne a Bilbao. El mecanismo que se utilizó para resolver el problema de alimentación planteado a la cabaña local fue el mismo que con los tratantes asturianos: introducir el ganado forastero en los pastos de Sierra Salvada Baja. El 6 de junio de 1675, Orduña, en los términos de "El Morquero», "Corralejo» y "Larrea», prendió ocho bueyes y el señor La Rasa fue multado con 1.500 reales, cantidad que hay que considerar abultada en relación al número de bueyes prendados, pero que no lo es respecto al número de ganado que, fraudulentamente, habían pastado, pero no habían sido sorprendidos y que rondaban la centena de cabezas (27).

Si bien Orduña se veía afectada por intereses que sobrepasaban

(25) AHMO, Pleitos y Sentencias, 1, 1, y Sentencias, 1, 1

(26) AHMO, Pleitos y Sentencias, 1, 1.

(27) AHMO, Pleitos y Sentencias, 1, 1. 
los estrictamente relativos a las producciones silvopastorales en Sierra Salvada, villa y ciudad intervinieron conjuntamente para defenderse de un uso abusivo de los pastos por parte de Llorengot.

En el siglo XIX, con motivo del acuerdo de 30 de abril de 1819, por el que Villalba y Orduña arrendaron pastos de Sierra Salvada a mil ovejas merinas trashumantes, a cambio de tres mil reales, Llorengot, alegando que tenía derecho a pastos en algunos de los términos que se habían asignado a las ovejas merinas y que, por tanto, le correspondía asimismo parte de la cantidad percibida, entabló demanda judicial contra Villalba ante la Chancillería de Valladolid. A la cuestión de arrendamiento se sumó el asunto de las multas por prendarias de ganado al temer probablemente Llorengot que Villalba intentase elevar su cuantía, como había sucedido en las prendarias de 1817 y 1819 a ganados de la tierra de Ayala.

Aún desconociéndose los términos territoriales en litigio, pero que, probablemente se localizaban en las partes más altas, el origen de las disputas parece derivarse de la aplicación de concesiones de servidumbres de pastos mutuas o convenios sobre prendarias, acordados entre Llorengot y Villalba de Losa. Estos compromisos de Villalba con terceros afectaban directamente a Orduña, por lo que la ciudad y villas, juntas, estudiaron los documentos que, en relación al tema, disponían, comunicándose entre sí la información relativa al asunto, que cada una de las entidades poseía, en el transcurso y evolución del conflicto (28).

Las diferencias, desde un principio, se encaminaron por la vía de la resolución y transacción amistosas. Con fecha 3 de noviembre de 1819, los representantes del lugar de Llorengot y de la jurisdicción de Villalba establecieron unas bases de acuerdo, que pueden interpretarse como unas normas y mecanismos consensuados del procedimiento a seguir en la resolución del problema.

Respecto al arrendamiento, los pasos a dar eran delimitar las partes derechohabientes, establecer criterios de reparto del dinero percibido, determinar la entidad encargada del cobro y aclarar si alguna de las partes, en consideración a que le correspondía la jurisdicción, podía proceder a arrendar los pastos sin conocimiento de los demás derechohabientes pero con la obligación de entregarle las prorratas correspondientes. En cuanto a las multas, los puntos a clarificar estriban en determinar los límites hasta dónde el ganado de Llorengot podía pacer bajo las multas prevenidas en los documentos y en estudiar, en base al tiempo transcurrido y su baja cuantía, la elevación de las mismas (29).

(28) AHMO, Acta de la sesión celebrada por el Ayuntamiento el 21 de julio de 1819; AHMO, Pleitos y Sentencias, 3, 14.

(29) El texto del acuerdo de 3 de noviembre de 1819 en AHMO. Pleitos y Sentencias, $3,14$. 
En los capítulos del acuerdo antecedente se incluía un aspecto, en el que Orduña no podía estar conforme: existiendo una comunidad de pastos a partes iguales, la jurisdicción no podia ser la base para que Villalba pudiera intervenir en arrendamientos de pastos sin conocimiento de Orduña, contradiciendo lo acordado en las Concordias de 1645 y 1659 (30). Probablemente por este motivo o, quizá por otras razones, todavía el 9 de mayo de 1820, Orduña no había decidido nombrar jueces compromisarios para resolver el problema creado con el arrendamiento de ovejas merinas; en dicha fecha, en carta enviada a Villalba, opinaba que no tenía inconveniente en que se arrendasen los pastos a ovejas merinas y en que los ingresos del alquiler quedaran en poder de Villalba, entre tanto se determinaban los puntos pendientes según los mecanismos establecidos en el acuerdo de 3 de noviembre de 1819 (31).

Las actas del Ayuntamiento de Orduña quedaron interrumpidas el 14 de abril de 1820 y no se reanudaron hasta el 12 de mayo de 1823. Entre los documentos y expedientes del archivo municipal tampoco consta alguno relativo al nombramiento de jueces compromisarios, a la escritura de compromiso o al pago de la prorrata correspondiente en los ingresos obtenidos del arrendamiento de ovejas merinas en Sierra Salvada Baja. Todo lo anterior da pie a pensar que Orduña no llegó a firmar el acuerdo de 3 de noviẹmbre, y que, incluso, el arrendamiento de pastos a ovejas merinas no llegó a cerrarse, lo que pudo venir motivado por la querella entablada por Llorengot.

Cuarenta años más tarde, hacia 1861, Llorengot prentendió que la superficie, en la que tenía servidumbre de pastos, abarcaba todo el ámbito de Sierra Salvada Baja, incluido el pozo del Lago y el mojón de "Cilatre» (32). Estas pretensiones debieron ser pasajeras pues, en caso contrario, Villalba y Orduña hubieran procedido a prendar ganados, de lo que no se tiene constancia alguna.

En resumen, los pretendidos derechos de Llorengot en la sierra se mantuvieron como una nebulosa de oscuros orígenes, contenido y extensión, sin llegar a concretarse ni clarificarse documental ni jurídicamente.

\subsubsection{Tierra de Ayala}

Con motivo de las prendarias que Villalba sometió a los ganados de la Tierra de Ayala el 4 de junio de 1817 y el 17 de junio de 1819, ésta demandó a aquélla por diversas cuestiones, entre las que se incluían la cuantía de las multas y el ámbito de su aplicación.

(30) AHMO. Acta de la sesión celebrada por el Ayuntamiento el 14 de noviembre de 1819

(31) AHMO, Pleitos y Sentencias, 3, 14.

(32) AHMO, Pleitos y Sentencias, 3, 14 
Tras la presentación de la demanda, Villalba se puso en contacto con Orduña (33). Entre 1819 y 1826 , el proceso legal quedó prácticamente paralizado; con fecha de 8 de julio de 1826 , Villalba obtuvo Real Provisión, por la que se citada a Orduña al juicio entre ella y la Tierra de Ayala (34). En los meses finales de 1826 y a lo largo de los años de 1827,1828 y 1829, en el que finalizó el pleito, Orduña y Villalba actuaron combinadamente en el proceso legal y en los costos derivados tanto de esto como en sus secuelas prendaria de 1865 (35).

Aunque el juicio tuvo un desenlace negativo para las pretensiones de Villalba y Orduña, ésta, con la citación al juicio por parte de la villa, obtuvo un reconocimiento expreso, si se quiere en una forma global, de los derechos que asistían a los vecinos de la ciudad y sus aldeas en Sierra Salvada Baja. En unas circunstancias de armonía entre ambas, el reconocimiento de la villa era de escasa entidad, pero el valor que tiene actualmente, en que Orduña se encuentra en una situación en la que tiene que demostrar que tiene derecho a acceder a los aprovechamientos de la sierra, tiene el valor de un testimonio difícilmente reprochable.

\subsubsection{Cura de Múrita}

Por el extremo sureste, la sierra lindaba con el monte Quinlleriz, perteneciente a los propios del pueblo de Múrita. El «Boletín Oficial de Ventas de Bienes Nacionales», con fecha 19 de agosto de 1860, anunció la venta del mismo, inscribiéndole con el número de inventario 1.151, evaluando su extensión en 95 fanegas y tasado su valor de subasta en 20.150 reales. El comprador del monte fue el cura de Múrita, Juan José de Ayala (36).

(33) AHMO, Pleitos y Sentencias, 3, 14

(34) AHMO, Pleitos y Sentencias, 3, 14.

(35) Los pleitos alcanzan la etapa álgida de trabajo en la fase de presentación de pruebas, interrogatorio de testigos, etc. En el proceso legal que nos ocupa, esta etapa se efectuó a partir del mes de septiembre de 1828. Para que el procurador señor Figuero afrontara los gastos ocasionados en la fase de probanza se le entregaron 680 reales, 500 por parte de Orduña y 180 por parte de Villalba, según consta en la correspondencia entre Orduña y el procurador en los meses de agosto y septiembre de 1828 (AHMO, Pleitos y Sentencias, 3/14). No se conoce la entrega de nuevas partidas de dinero. De todos modos, la efectuada en 1828 presenta una desigualdad en las aportaciones que no se especifica en base a qué criterios se llevó, pero que no se piensa que, en este caso, se siguiese un criterio diferente de partes iguales. Probablemente fue un adelanto, posteriormente reintegrado. En caso de ser asi, Orduña tuvo más suerte que en el pleito que siguió a la prendaria de 1865 , pues por el acta de 15 de noviembre de 1881 puede comprobarse que, no obstante haber transcurrido más de una decena de años en la promulgación de la sentencia, Villalba no había endosado a Orduña la parte de costas que le correspondia, y que habian sido adelantadas por el municipio vizcaino: «... la expresada junta de Villalba está adeudando a este municipio la parte de costas correspondientes por el pleito que, sobre los expresados aprovechamientos, se siguieron en 1867 contra algunos pueblos de Ayala, cuyas costas se satisfacieron por este Ayuntamiento y tiempo sobrado es de que el de Villalba reintegre de la parte que le corresponde" (AHMO. Actas).

(36) AHMO, Sierra Salvada, 13. 
El cambio en la propiedad del monte desencadenó una serie de diferencias y cuestiones referentes a usurpación, reconocimiento de servidumbres de pastos, aguas y paso, recaidas sobre el predio, en favor de las entidades y pueblos que, con Múrita, disfrutaban del monte colindante por el norte, es decir, de Sierra Salvada Baja, etc.

A pesar de que la finca vendida se hallaba amojonada, pretextando estar incluidos en la venta, procedió a cultivar terrenos de las fincas colindantes: por el este, en la dehesa mayor de Múrita y monte de Santa Agueda; por el norte, en Sierra Salvada Baja, campos y valles contiguos a la barrera de Balcabala hasta alcanzar el pozo de Monte Redondo, y en la dehesa de Corcora, y por el oeste, en las laderas de las Fontallejas, fuente del mismo nombre, valle La Encina y barrera del Encinal. El cultivo intrusivo alcanzaba unas 850 fanegas, cifra escandalosamente superior a las 95 aranzadas que le otorgaba de superficie el «Boletín Oficial de Ventas de Bienes Nacionales" (37).

Al tener conocimiento de lo anterior, Orduña, en sesión de 7 de abril de 1861, acordó el envio de un oficio a Villalba, en que se le comunicaba estos hechos y se le solicitaba la celebración de una reunión conjunta para tratar el asunto, lo que Villalba aceptó según se dio cuenta en la sesión de 14 de abril de 1861 (38). Fruto de esta reunión fue el escrito conjunto de Villalba y Orduña al gobernador civil de Burgos, por el que le solicitaban el reconocimiento de mojones (39), lo cual se ignora si se llegó a. celebrar.

Independientemente de la ejecución del deslinde, lo que sí parece que se produjo fue el cese por parte del cura de Múrita en su desorbitado comportamiento. Este cura, incluso llegó a reconocer servidumbres de aguas, pastos y paso en el monte Quinlleriz en favor de los pueblos que disfrutaban de los aprovechamientos de la finca colindante por el norte, es decir, en favor de Villalba, Múrita, Mijala, Zaballa y Orduña. Esto sucedia el 29 de noviembre de 1861, unos seis meses más tarde del conocimiento del comportamiento abusivo $y$, solamente, se explica en un contexto de relaciones distendidas, dentro del cual el cura de Múrita elegió la cesión voluntaria y gratuita de las servidumbres mencionadas, renunciando a cualquier reclamación legal sobre el asunto a cambio de que los pueblos beneficiados por la cesión se obligasen a lo mismo (40). En el caso de que Sierra Salvada Baja fuese sacada a la venta, la concesión de servidumbres quedaba reducida a los vecinos de Múrita.

(37) AHMO, Sierra Salvada, 15

(38) AHMO, Acta de la sesión celebrada por el Ayuntamiento el 14 de abril de 1861

(39) AHMO, Sierra Salvada, 15.

(40) AHMO, Sierra Salvada, 15 
Las servidumbres, con un origen anclado en un uso indiferenciado y mancomunado de los pastos, no siempre fueron respetadas como sucedió hacia 1870, año en el que los vecinos de Múrita acusaron a Juan José Ayala de interceptar la cañada de paso y prohibir el uso de las aguas del pozo de las Sernas por parte de los ganados. A instancias de Múrita, se abrió un expediente por la alcaldía de Villalba; la cual, por oficio de 26 de marzo de 1870 , daba cuenta a Orduña del asunto y le rogaba el nombramiento de una comisión para que, reunida con los representantes de la misma, deliberasen y acordasen lo más justo $y$ acertado en el tema, citándole para las ocho de la mañana en el término de la barrera de Balcabala (41). La resolución del expediente nos es desconocida pero lo más probable es que fuese contraria a las pretensiones del propietario del monte Quinlleriz.

Por lo demás, el cura de Múrita fue una persona emprendedora. Hacia 1866 poseía 500 carneros y los introdujo en la sierra, lo que, por el desequilibrio pastos-cabaña ganadera que ello suponia, provocó las protestas de los vecindarios derechohabientes. En el caso de Orduña, la protesta se elevó hasta el arzobispo de Burgos, al que, por junio de 1866, dirigieron un escrito quejándose del comportamiento del cura de Múrita, que estimaban «ajeno del carácter sacerdotal y prohibido por las instituciones canónicas» (42).

\section{DISCUSION POR EL AMBITO TERRITORIAL OBJETO DE PROPIEDAD Y APROVECHAMIENTOS PRO INDIVISOS}

En el apartado anterior, el lector ha podido comprobar cómo, en unas circunstancias determinadas, tanto internas (conflictos entre los pueblos parcioneros en la sierra) como externas (defensa de intrucciones o pretensiones a los aprovechamientos de la sierra por parte de terceros) en diferentes épocas y ante los hechos relatados, Villalba y aldeas, juntas o por separado, han recnocido de manera directa e indirecta los derechos que asisten a Orduña en relación a la Sierra Salvada Baja.

Paralelamente, por cuestiones y en momentos distintos, Villalba $y$ aldeas han venido cuestionando la superficie territorial de la sierra, en la que Orduña tenía derecho. Ha sido una forma, si se quiere soterrada pero real, de incordiar la posesión y disfrute de la sierra a Orduña y aldeas.

En los apeos de la segunda mitad del siglo XVII, tras la visita de los mojones de la dehesa de Monte Redondo, figuraban cuatro

(41) AHMO, Sierra Salvada, 15.

(42) AHMO, Actas, junio 1866. 
mojones: "Cabaña Vieja» (también "Cueva de Ongoño» o "Ayuela de Ongoño»), el último de los hitos que circunscribía la dehesa de Monte Redondo, "Encrucijadas" o "Crucijadas de Berdina», "Cerro de Gobeña» o "Roble Horcado» ("Arcado» y «Horquijado») y «Pozo del Lago» (290).

Por aquellas fechas, Villalba y Orduña disputaban acerca de la facultad de arrendamiento de los aprovechamientos en la sierra, en especial de los pastos. Las diferencias se zanjaron en sendas concordias de 1645 y 1659. En esta última, Villalba reconocía que había defendido la exclusión de Orduña y su tierra en el disfrute y comunidad en los aprovechamientos en la superficie de Sierra Salvada Baja, situada el sur, contra Villalba, de la línea de mojones recogida en los apeos de la mitad del siglo XVII, es decir, "Cabaña Vieja», "Encrucijadas», "Cerro de Gobeña» y "Pozo del Lago», lo que le había llevado erróneamente a arrendar pastos en términos en los que compartía el aprovechamiento con Orduña.

En el apeo de 1661, siguiendo a la concordia de 1659, se manifiesta que entre las dehesas de Monte Redondo y Lago de San Juan no debía existir ningún mojón, derribándose dos, que se encontraron entre las mismas. Por el acta del apeo, que no recoge todos los mojones colocados en 1494, se tiene especial cuidado en separar y deslindar la visita por separado de los mojones de las tres dehesas, evitándose así, por hacer un apeo «reducido», la deducción de la existencia de una línea de mojones entre Cabaña Vieja y Pozo del Lago, los dos últimos mojones que, respectivamente, delimitaban a las dehesas de Monte Redondo y Lago de San Juan (43)

La "visita» reducida de mojones, acompañada casi siempre de una clara separación de los mojones revisados, según correspondieran a alguna de las dos dehesas referidas en el apeo de 1494, se repitió en las actas de los apeos de $1664(44), 1673$ (45), 1676 (46), 1679 (47), 1961 (48), 1761 (49) y 1731 (50). A partir

(43) Ermita de San Bartolomé, 5 de septiembre de 1661, escribanos: Diego Sarachaga y Juan de Sarría (AHMO. Apeos Villalba, 2)

(44) Peña de San Bartolomé, 6 de noviembre de 1664, escribano: Francisco de Garay (AHMO, Apeos Villalba, 22)

(45) Ermita de San Bartolomé, 11 de julio de 1673, escribano: Juan Bautista Elordui (AHMO, Apeos Villalba, 21)

(46) Ermita de San Bartolomé, 9 de septiembre de 1676, escribanos: Juan de Mendijur y Francisco de Pinedo Cascajo (AHMO, Apeos Villalba, 19).

(47) Ermita de San Bartolomé, 17 de noviembre de 1679, escribano: Francisco de Ulizar (AHMO, Apeos Villalba, 28).

(48) Ermita de San Bartolomé, 16 de julio de 1691, escribanos: Mateo de Joceno y Antonio de la Torre (AHMO, Apeos Villalba, 16).

(49) Portillo de la Peña de San Bartolomé, 12 de noviembre de 1716, escribanos: Juan Jiménez-Bretón y Juan Bautista de la Fuente (AHMO, Apeos Villalba, 13).

(50) Portillo de la Peña de San Bartolomé, 6 de julio de 1731, escribano: Matias de Padura (AHMO, Apeos Villalba, 3). 
del apeo de 1676, el primer mojón apeado en la dehesa del Lago solía ser el designado en las actas de apeo como «entre los dos caminos, el uno, que va de Gobeña para Zaballa, y el otro, de Goldecho para Mijala», y el último, el «mojón que está pegante al pozo del Lago».

Villalba defendía un línea de mojones, con más o menos entrantes, en forma de sierra, pero progresiva en dirección este, que sólo era derivable de las actas de apeos levantadas a partir de la segunda mitad del siglo XVII, pero que, a la luz del apeo de 1494, era descartable, pues en él se colocan mojones en tres dehesas, separadas una de otra, en una dirección más o menos circunvalada, sobre todo en lo que respecta a las dehesas de Monte Redondo y dehesa del Lago. Los mojones colocados en 1494 eran señales que indicaban a Orduña la prohibición de aprovechamientos de madera y roza en los términos acotados, pero no afectaban al aprovechamiento de pastos, como pretendió Villalba en el siglo XVII, o a la jurisdicción, como parece que Orduña llegó a plantear en el siglo XVIII.

A finales del siglo XVIII, el apeo de 1794, una vez iniciado, se interrumpió, sucediendo lo mismo en 1796. El motivo de las interrupciones fue la pretensión de Villalba de apear la línea divisoria de mojones integrada por "La Ayuela», "Crucijadas de Mijala» y "Alto del Cerro de Gobeña», a lo que Orduña, amparándose en la Real Carta Ejecutoria de 1494, se opuso (51). En el trasfondo de las disputas sobre mojones se debatían límites de propiedad $y$ aprovechamientos en la sierra: Villalba, como en el siglo XVII. pretendían que Orduña no tenía derechos a los aprovechamientos al sur, contra Villalba, de los tres mojones de "La Ayuela", "Crucijadas» y "Cerro de Gobeña» (52).

Curiosamente, unas diferencias radicadas sobre límites de propiedad y aprovechamiento de pastos se dirimieron con una división de vuelo y la permanencia en común de aguas y pastos, según convenio de 19 de septiembre de 1798. El interés crece si se considera que la divisoria establecida en el reparto del arbolado coincidía en gran parte con los límites por los que discurrían los mojones origen del conflicto: los hitos a colocar para divisoria de arbolado eran "Peña Goldecho», "primer mojón de la Cobanera», "Alto de Gobeña», "Crucijada de Mijala», "Pozo de Ongoño», "Calleja de las Verduras», "Cuesta la Horca» y "Peña de San Bartolomé». A la vista de todo ello, el desenlace ha de interpretarse como contrario a las pretensiones defendidas por Villalba, que volvía a reconocer lo erróneo de sus planteamientos.

(51) AHMO, Sierra Salvada, 1

(52) AHMO, Villalba, 21. 
En los apeos de los siglos XIX y XX se dejó de apear las tres dehesas según constaba en el apeo inserto en la ejecutoria de 1494 para visitar los mojones resultantes del convenio de arbolado que, firmado en 1798, llegó a aplicarse y materializarse, con algunas diferencias respecto a lo acordado en el convenio, por el apeo de 28 de octubre de 1847.

El apeo de 5 de septiembre de 1878, puso de manifiesto la reaparición de cuestiones, que coleaban desde el XVII convirtiendo la línea divisoria del arbolado en límites de propiedad y aprovechamiento para Orduña y sus aldeas. El apeo finalizaba con un párrafo, que mantenía, en todo su valor y vigencia, las ejecutorias y demás documentos relativos al asunto (53). Esta última declaración contrarrestaba cualquier futura utilización que Villalba pudiera realizar de este documento.

El acta de 16 y 19 de abril de 1943, respecto a lo que aquí se analiza, es una copia casi idéntica del texto del acta del apeo de 5 de septiembre de 1878, con lo que la cuestión se trasladó hasta este siglo, pero con la salvedad de que, en esta ocasión, los representantes de Orduña aceptaron la conversión de la divisoria de mojones de vuelo en límites respecto a la posesión y aprovechamiento para Orduña tan solo con carácter provisional por considerar que sus derechos de pastos y aguas en común con Villalba, se extendian por toda la Sierra Salvada (54).

(53) En el acta de amojonamiento de 1878 (Alto de la Horca, 5 de septiembre, secretarios: José Salazar y Lucio Garcia), la divisoria de arbolado se transforma en límites de propiedad y aprovechamientos para los vecinos de Orduña $y$ sus aldeas: "... que todo el terreno comprendido desde la línea de los mojones reconocidos hacia el norte corresponde hasta las peñas de Orduña en cortas, rozas y aprovechamientos a la ciudad de Orduña, y que los demás montes bajos $y$ dehesas son jurisdicción privativa y propia de Villalba y sus aldeas, que toda la parte del mediodia de dichos mojones cuya línea no pueden rebasar ganados de dicho Orduña ni Arrastaria, y que en cuanto al aprovechamiento de pastos y aguas son iguales ambas corporaciones de Orduña y Villalba en el terreno comprendido al norte de los mojones") (AHMO, Sierra Salvada, 4). En 1878, Orduña no presentó protesta alguna, probablemente, por la coletilla final del apeo, que afirmaba el valor y vigencia de las ejecutorias y demás documentos relacionados con el asunto, a los que se sometian y con los que estaban en contradicción manifiesta "... en este estado los peritos apeadores dieron por terminada la operación dejando en toda su fuerza y vigor todas las ejecutorias y demás documentos que se hallan en relación a este asunto...) (AHMO, Sierra Salvada, 2).

(54) Al final del documento del acta del apeo de 1943 (La Horca, 17 y 19 de abril, secretarios: Santiago Ezcurra y Antonio Pineda), constan una serie de declaraciones de Villalba y Orduña: "A) por parte de Villalba de Losa y sus aldeas UNICA: Que todo el terreno comprendido desde la línea de los mojones reconocidos hacia el norte. corresponde hasta la Peña de Orduña en cortas, rozas y aprovechamientos a la ciudad de Orduña y que los demás montes bajos y dehesas son jurisdicción privativa y propia de Villalba y sus aldeas y que en toda la parte de mediodia de dichos mojones, no pueden rabasar la linea, los ganados de Orduña, y que en cuanto al aprovechamiento de pastos y aguas, son iguales ambas corporaciones de Orduña y Villalba en el terreno comprendido al norte de los mojones, con cuya condición dan a este apeo como definitivo. B) Por parte de Orduña se hizo constar: UNICA: que aceptan la anterior declaración y apeo, tan solo con carácter provisional, ya que no fundándose en Reales Mercedes Cartas Ejecutorias y Concordias de diferentes fechas de un modo especial la 
Independientemente del contenido de las actas de 5 de septiembre de 1878 y del 16 y 19 de abril de 1943, el disfrute de los pastos y demás aprovechamientos del suelo, en las épocas posteriores a los mismos, se ha venido distinguiendo como, secularmente lo ha sido, por el condominio. Ambos apeos se han mantenido vigentes en lo relativo a la mojonera, implantada en la sierra por el apeo de 28 de octubre de 1847 con los fines de repartirse el arbolado, pero su valor ha sido nulo en lo que respecta a los aprovechamientos del suelo.

La discusión entablada por Villalba acerca del territorio que abarcaban los derechos de Orduña en la sierra, secularmente, ha sido la fórmula elegida por los losinos para intentar demostrar la superioridad de sus derechos en la sierra frente al municipio vizcaíno. En las relaciones intercomunitarias, este debate representa un cuestionario secular de la presencia del municipio de Orduña en la sierra $y$, en último término, trata de sentar las bases psico-sociológicas y mentales para erradicarlo del disfrute y aprovechamiento de la sierra, lo que está en evidente contradicción con el secular y permanente uso de los aprovechamientos de Sierra Salvada por parte de Orduña, uso sustentado y confirmado por la abundante documentación legal contenida en su archivo municipal.

\section{EXCEPCION DE SIERRA SALVADA BAJA}

\section{DE LA DESAMORTIZACION E INCLUSO EN EL CATALOGO DE MONTES DE UP}

La Ley de 1 de mayo de 1855, que declaraba en estado de venta, entre otros, las fincas de propios, pertenecientes a los pueblos y municipios, exceptuó de la misma aquellos terrenos, que fuesen de aprovechamiento común. La desamortización de los bienes de pueblos y municipios fue un proceso largo, que arrancó en el XIX pero que, legalmente, no puede darse por finalizado hasta la década de los treinta del siglo $X X$.

En relación a la Sierra Salvada Baja, sin que, documentalmente, conste el motivo, aunque, lógicamente, se ha de sospechar que estuviera relacionado con la posible inclusión de la sierra en la venta desamortizadora, Villalba y Orduña trabaron contactos para excluir la sierra de la venta, allá por junio de 1861, en base al criterio de aprovechamiento común (55). En el mes de julio, con los gastos a medias, levantaron información posesoria ante el notario de Villar-

Concordia de 30 de noviembre de 1659, es sentir general de sus vecinos que los derechos de la ciudad de Orduña y sus aldeas, se extiende a toda la Sierra Salvada en común con Villalba» (AHMO, Sierra Salvada).

(55) AHMO, Acta de la sesión del Ayuntamiento celebrada el 30 de junio de 1861. 
cayo (56) y el expediente de excepción se incoó ante el Gobierno Civil de Burgos a primeros de agosto con el número 738 (57).

El expediente siguió su curso a lo largo de 1862. Por las actas municipales del Ayuntamiento de Orduña, se conoce que, en el mes de julio, se presentaron los documentos que los respectivos pueblos poseían en relación a la sierra (57); en agosto, al ser incluidas la Sierra Salvada Baja entre los bienes sacados a la venta, tramitaron nueva instancia de solicitud de excepción (58); en septiembre, se procedió a la medición de la sierra por el perito agrónomo Justo Loredo, corriendo los gastos por partes iguales (59) y, en octubre, el ingeniero de montes de la provincia de Burgos hizo una visita ocular de la sierra (60).

La tramitación de los expedientes incoados para exceptuar de las ventas desamortizadoras las sierras de los pueblos de aprovechamiento común fue un proceso largo. La cantidad y calidad de la documentación exigida, la inercia de los pueblos y de la administración, el extravio de la documentación, etc., provocaron grandes dificultades y atrasos en la resolución y determinación de los mismos, concediéndose y prorrogándose los plazos en sucesivas ocasiones (1865, 1868, 1870, 1871, 1886, 1896, etc.).

Pretensiones de incluir montes y términos de Sierra Salvada Baja entre las fincas enajenables por aplicación de la legislación desamortizadora ha habido varias. A lo reseñado para 1861 y 1862 , hay que sumar lo sucedido en este punto en 1880 , en 1895 y en 1897. en fechas próximas al catálogo de 1901.

Hacia finales de 1880, ambos pueblos, corriendo con los gastos a medias, tramitaron la anulación de la inclusión de montes y términos de Sierra Salvada del listado de bienes nacionales incluidos en las ventas desamortizadoras. Así, el acta de 19 de diciembre de 1880 habla de un oficio, remitido por la alcaldía de Villalba de Losa, en que demandó a Orduña el pago de 75 pesetas en concepto de gastos causados en la gestión de la anulación de la venta de Sierra Salvada Baja (61).

En agosto de 1895, la administración de Hacienda de la provincia de Burgos remitió un oficio al alcalde de Orduña, por el que le requería aclaraciones relativas a las divisiones habidas en la sierra y a información posesoria de la misma. En el escrito, la administración provincial burgalesa le notificaba al Ayuntamiento

(56) AHMO, Sierra Salvada, 13.

(57) AHMO. Acta de la sesión del Ayuntamiento celebrada el 18 de julio de 1862.

(58) AHMO, Sierra Salvada, 12.

(59) AHMO. Acta de la sesión del Ayuntamiento celebrada el 21 de septiembre y el 30 de noviembre de 1862; AHMO. Sierra Salvada, 13.

(60) AHMO, Sierra Salvada, 13.

(61) AHMO. Acta de la sesión del Ayuntamiento celebrada el 19 de diciembre de 1880. 
de Orduña que la Subsecretaría del Ministerio de Hacienda le había devuelto el expediente promovido por los Ayuntamientos de Ayala, Orduña y Villalba de Losa para exceptuar de la desamortización en concepto de aprovechamiento común a la Sierra Salvada Alta y Baja. Todo esto sucedía, existiendo la Real Orden de 31 de enero de 1881 del Ministerio de Hacienda, por la que, en concepto de aprovechamiento común, se había exceptuado de la venta a la Sierra Salvada Alta.

El administrador de bienes del Estado en la provincia de Burgos, con fecha de 7 de julio de 1897, encargó a diversos peritos la tasación de diversos terrenos, bienes de propios, que aún, no habian sido vendidos. Lo interesante del caso es la actuación de Lorenzo Andino, el perito de Hacienda que intervino en el Valle de Losa, el cual, por iniciativa propia, incluyó en la tasación los montes de "Anzalón», "Dehesa del Agua» y "Los Valles», todos ellos localizados en la "Sierra Salvada Baja». El asunto no llegó a tener más trascendencia al quedar desautorizada la actuación del perito por no tener facultades para realizar la operación comentada (62).

Estos tres casos constituyen tres ejemplos de las vicisitudes pasadas a lo largo del período de vigencia de la legislación desamortizadora, particularmente, entre los años 1855 y 1901, por los montes y términos de Sierra Salvada Baja. No son los únicos, pues, por la documentación consultada, Orduña y Villalba realizaron por este motivo diversas gestiones en los años 1865 y 1888 (63), años que coinciden con la culminación de los trabajos del catálogo de 1862 y las relaciones de montes de 1862 y 1877.

La inclusión y, con ello, la excepción de las ventas desamortizadoras, de montes y términos comprendidos en Sierra Salvada Baja no llegó hasta la formación del catálogo de montes de utilidad pública aprobado por Real Decreto de 1 de febrero de 1901. La relación de montes del catálogo provincial de Burgos apareció en la "Gaceta de Madrid» del 13, 24 y 29 de abril y del 31 de mayo de 1901. En el último boletín citado, dentro del partido judicial de Villarcayo con los números 443, 447 y 452, se incluyeron respectivamente los montes de Anzalón, Dehesa del Agua y Valles, montes y términos englobados en Sierra Salvada Baja.

En el catálogo de montes de utilidad pública de la provincia de Burgos, al igual que sucedió en el de Alava en relación a la parte más alta (64) no aparece ningún monte inscrito a nombre de Sierra

(62) AHPB, Leg. 274, 73.

(63) AHMO, Sierra Salvada, 13

(64) La Sierra Salvada, en su parte alavesa, cuando se elaboró el catálogo de montes de utilidad pública de la provincia de Alava (1900), fue inscrita en ocho montes distintos, los números $2,3,27,29,82,86$ y 87 . Entre paréntesis, tras las denominaciones de los montes números 27 y 29 , se especifica Sierra Salvada. 
Salvada, ni por tanto, Sierra Salvada Baja, denominación usada en las gestiones referentes a la solicitud de excepción de la desamortización. El catálogo, a la hora de la inscripción, divide en Sierra Salvada Baja en tres montes con los nombres de Anzalón, los Valles y Dehesa del Agua. Dos de los nombres citados coinciden con dos de las dehesas contempladas en la ejecutoria de 1494 pero, únicamente, en el caso de Anzalón, son asimilables la extensión y límites proporcionados por catálogo y ejecutoria.

El catálogo presenta otra novedad interesante. La pertenencia, en lo que respecta a los pueblos burgaleses, no es asignada de una forma conjunta a Villalba y aldeas, como en las ejecutorias, concordias y demás documentos se relata: asi, los montes Anzalón, para los pueblos de Villalba y Múrita, los valles para Villalba, y, la dehesa del Lago para Villalba y otros.

\section{ENFRENTAMIENTO FRONTAL DE VILLALBA DE LOSA CON ORDUÑA POR LA PROPIEDAD DEL MONTE «DEHESA DEL AGUA»}

El siglo XIX, en un análisis general, en la historia de las relaciones intercomunitarias por los aprovechamientos de la sierra, se caracterizó por ser un período de armonía y buena vecindad. En este clima, Villalba y aldeas, con Orduña y las suyas, en estrecha colaboración, tramitaron la excepción de la sierra de la desamortización y, consiguientemente, su inscripción en el Catálogo de Montes de Utilidad Pública.

La inscripción en el Catálogo sucedió tras casi cuarenta años de solicitar la excepción de la desamortización, y este período de tiempo no pasó en balde, pues tras él se introdujeron ciertos cambios que pueden parecer nimios, pero que acarrearian trascendentales consecuencias para el futuro, particularmente para Orduña: así, la solicitud de la excepción se hizo conjuntamente entre Villalba y Orduña, pero su nombre, de forma diferenciada, no figura entre los dueños del monte anotados en el Catálogo.

En los primeros cuarenta años del $x X$, las relaciones intercomunitarias se mantuvieron amistosas, sin que surgieran problemas por los aprovechamientos ni por ninguna otra cuestión: las cosas cambiaron a partir de los cuarenta, en los que Villalba prendó ganados de Orduña en diferentes ocasiones. En una situación de enfrentamiento comunitario, argumentando que su nombre no figuraba en el Catálogo y amparándose en la presunción de propiedad, sólo, modificable en sentencia de los tribunales, Villalba podia estorbar e incluso impedir el uso de los aprovechamientos de la sierra por parte de Orduña, la cual, si esto sucediera, para 
disfrutar de los productos de la sierra, se vería obligada a acudir a los Tribunales. Orduña debió tomar conciencia de ello y, probablemente, fue el mentor de la declaración conjunta, inserta en el apeo de 17 de abril de 1943, por la que aclaraban al Distrito Forestal que el "otros», registrado en la casilla de pertenencia en el monte Dehesa del Agua, número 447 del Catálogo, integraba a Mijala, Múrita, Zaballa y Ayuntamiento de Orduña, que, junto a Villalba, eran sus cinco únicos y verdaderos dueños (65).

Hasta 1955, la aclaración acerca de la pertenencia asignada en el Catálogo de Montes de Utilidad Pública, contenida en el apeo de 17 de abril de 1943, bastó para garantizar el disfrute de los aprovechamientos de la sierra por parte de Orduña, salvaguardándola de los ataques de los losinos. Tras los problemas iniciales, surgidos en la subasta de 1945 y zanjados amistosamente, las celebradas en 1946 y 1951 se sucedieron sin contratiempos.

La celebración de la subasta del aprovechamiento de pastos en 1955 para el monte la Dehesa del Agua, desencadenó la afloración del conflicto por la propiedad de la sierra de una forma clara y tajante. Los motivos que impulsaron a los losinos para impedir la participación en la mesa de la subasta a los representantes del ayuntamiento orduñés radicaban en el dominio sobre el monte.

Orduña, como fórmula para evitar futuros conflictos, pretendió, sin conseguirlo, la rectificación del "otros» que figuraba en la casilla de pertenencia referente al monte número 447, Dehesa del Agua, del Catálogo de Montes de Utilidad Pública de Burgos (66). La rectificación se presentaba como una aclaración del vocablo "otros» sin, por ello, plantear una impugnación de la pertenencia asignada a Villalba de Losa (67).

(65) El acta de apeo de 17 de abril de 1943, recogia tres declaraciones: la efectuada por Villalba de Losa y aldeas, la introducida por parte de Orduña y la formulada conjuntamente por las dos entidades. Esta última aludía a la asignación de pertenencia del monte número 447 del catálogo de montes catalogados de la provincia de Burgos, en los siguientes términos: «C) AMBAS PARTES, como dueñas del monte señalado el número 447 del catálogo de 1901 con el nombre de "Dehesa del Agua" como de pertenencia de Villalba de Losa y otros, acuerdan aclarar al distrito forestal de Burgos, que la palabra "OTROS" se entiende por Mijala. Múrita, Zaballa y Ayuntamiento de Orduña, que con Villalba, son sus cinco únicos y verdaderos dueños" (AHMO, Sierra Salvada)

(66) AHMO, Sierra Salvada, 19.

(67) El Ayuntamiento de Orduña, teniendo presente la legislación forestal en la materia, planteó la rectificación del catálogo como aclaración al mismo para contrarrestar la interpretación de impugnación que, de ella, podía hacer como, realmente, lo hizo Villalba de Losa. Asi, en el escrito de reclamación de 16 de mayo de 1959, se decia: "... no se trata de impugnar la pertenencia o titularidad de los montes antes indicados, sino de aclarar que en las palabras y OTROS, que constan en el catálogo, respecto de la DEHESA DEL AGUA, hay que estimar comprendiendo al Municipio de Orduña ...) (AHMO, Sierra Salvada). El recurso de reposición, promovido, el 8 de mayo de 1961, por Orduña, en relación a la Orden ministerial de 8 de mayo de 1961, refleja similares términos y contenido en relación a la rectificación del catálogo en lo que respecta al monte "Dehesa del Agua». 
Villalba, por el contrario, interpretó que la aclaración pretendida por Orduña suponía una modificación de la asignación de la pertenencia establecida en el Catálogo, lo que solamente podia suceder previo juicio declarativo ordinario de propiedad ante Tribunales civiles (68).

En la resolución administrativa del expediente, el Ministerio de Agricultura, por Orden de 15 de marzo de 1961, reconoció, en fávor del Ayuntamiento de Orduña, la existencia de una servidumbre de aprovechamiento de pastos y aguas en el monte «Dehesa del Agua», cuyo disfrute correspondía, por partes iguales, a los municipios de Orduña y Villalba de Losa, debiéndose reflejar esta servidumbre en el Catálogo de Montes de Utilidad Pública. Por lo que respecta a los apartados relativos a la propiedad de la finca forestal, la via gubernativa quedaba agotada, y Orduña, si lo deseaba, podía acudir a los Tribunales. Tanto Villalba como Orduña interpusieron recursos de reposición contra la resolución de 15 de marzo de 1961, siendo desestimados, respectivamente, por Ordenes de 7 de julio y 1 de septiembre de 1961.

Tras apelación de Villalba de Losa, por sentencia de 11 de junio de 1963, admitiendo defectos de forma en el procedimiento seguido en la tramitación del expediente, y sin entrar en el fondo de la reclamación promovida por el Ayuntamiento de Orduña, la Sala Cuarta de lo Contencioso-Administrativo del Tribunal Supremo invalidó y anuló lo actuado en el expediente administrativo: «... a partir de la propuesta del ingeniero jefe del Distrito Forestal de Burgos de treinta de noviembre de mil novecientos sesenta, en el expediente administrativo de razón y reponemos éste al estado que tenía antes de formularla, para evacuar el trámite de audiencia de que se hizo mérito y continuar después de practicado debidamente la instrucción de las diligencias con nueva resolución, no se hace imposición de costas» (69).

En el pleno de 7 de agosto de 1963, la Corporación orduñesa, enterada del contenido de la sentencia, acordó pacticar las gestiones necesarias ante el Distrito Forestal de Burgos, a fin de que supliese la omisión cometida, motivo de la anulación, acelerase la tramitación de la nueva resolución y adoptase las medidas condu-

(68) Villalba, Múrita, Mijala y Zaballa, en el escrito de alegaciones, de 30 de septiembre de 1959, valoraban la aclaración pretendida por Orduña respecto al catálogo provincial de montes de utilidad pública de Burgos como una declaración de derechos para la que, solamente, eran competentes los tribunales ordinarios. "El procedimiento aquí iniciado por Orduña no puede, pues, admitirse para los fines que persigue, pues lo que dice ser "aclaración" es en realidad "declaración de un derecho", por lo cual el expediente iniciado le podrá servir únicamente como via gubernativa o administrativa previa a un juicio declarativo ordinario y nada más" (AHMO, Sierra Salvada).

(69) AHMO. Sierra Salvada. 
centes a evitar que, entretanto, los ganaderos de Orduña pudiesen disfrutar de los pastos, al menos, en la Dehesa del Agua (70). A pesar de los escritos que por esta causa el Ayuntamiento le envió, al menos, con fechas de 9 de septiembre de 1963 y 8 de junio de 1964, todavía en esta fecha la administración forestal no había subsanado sus errores formales, que fueron los que provocaron la anulación del expediente (71).

La ejecución de la sentencia de 11 de junio de 1963 quedó paralizada hasta 1983, año en que el ICONA de Burgos inició lo que puede considerarse la segunda fase del expediente administrativo que, tras las transferencias de competencias a las Autonomías, correspondió resolver a la Consejería de Agricultura, Ganadería y Montes de la Junta de Castilla y León, la cual, mediante Orden fechada en Valladolid el 21 de enero de 1986, se inhibió y remitió a Orduña a los Tribunales ordinarios al estimar que es a éstos a quien correspondía conocer y decidir en relación con la misma.

Tal como prescribe la legislación forestal en cuestiones dominicales, la Administración, en las diferentes resoluciones tomadas al respecto, se ha inhibido y ha remitido a Orduña a los Tribunales civiles ordinarios, competentes en la materia, para resolver las reclamaciones, que mantiene sobre el monte Dehesa del Agua.

\section{CONCLUSIONES}

1. La Carta Ejecutoria de 1494 refleja una comunidad de aprovechamientos en el conjunto de Sierra Salvada Baja, con las excepciones de la madera, en cuanto aprovechamiento sobre las dehesas apeadas y de la Dehesa de Anzalón respecto al ámbito territorial.

El Convenio de 1798 y su aplicación material, a través del apeo de 1847, modificó el uso de la madera, simplificando su aprovechamiento: de haber zonas privativas (las dehesas) junto a otras, que eran comuneras, se pasó a la distribución del monte en dos porciones que quedaban reservadas para disfrute privativo de cada una de las partes.

(70) La lectura del fallo de la sentencia del Tribunal Supremo, de 11 de junio de 1963, se realizó en la sesión de 7 de agosto de 1963. La reacción de la corporación fue la siguiente: «Enterada la Corporación, lamentó lo sucedido acordando practicar gestiones diligentes a fin de que el Distrito Forestal de Burgos, suple la omisión cometida causa de la anulación recabando a la vez de la Dirección General acelera la nueva resolución y adopte medidas conducentes a evitar que mientras tanto, la ganadería de Orduña pueda continuar disfrutando de los pastos, por lo menos en la Dehesa del Agua pues caso contrario se infringiría un daño inmenso a los ganaderos del municipion (AHMO, Actas).

(71) AHMO, Sierra Salvada. 
2. Las Concordias de 1645 y 1659 establecieron la igualdad de ambas entidades derechohabientes a la hora de comercializar $y$ arrendar las producciones de la sierra, con exclusión de la madera comprendida en las dehesas.

Con la desamortización, las dos partes, conjuntamente y con gastos a medias, en 1861 y en 1880 (72), gestionaron la excepción de la venta del monte, con lo que ambas hicieron uso de su facultad de decidir sobre su entrada 0 no en el mercado inmobiliario, o sea, sobre su venta o conservación.

3. Las Concordias de 1645 y 1659 facultaron a las dos partes para intervenir en la defensa del monte contra aprovechamientos abusivos (asunto de las prendarias). Hasta el reparto del arbolado, la facultad reseñada no atañía, en lo que respecta a Orduña, a la madera de las dehesas, pero, una vez distribuido el vuelo, la defensa contra delitos forestales la ejercía cada entidad en su porción.

En los casos de disputas y conflictos con terceros, entidades dueñas de fincas colindantes, casos de Llorengot, de Ayala, del Cura de Múrita por el monte de Quinlleriz, las estrategias, las actuaciones, los planteamientos, etc., han sido resultado de esfuerzos conjuntos, repartiéndose a partes iguales los gastos de los mismos.

(72) La resolución, contenida en la Orden de 21 de enero de 1916 de la Consejeria de Agricultura, Ganaderia y Montes, viene precedida de un visto y cuatro considerandos que, a continuación, se reflejan:

"Vista La Ley de Montes de 8 de junio de 1957, en sus artículos 16 y 17; el Reglamento de Montes de 22 de febrero de 1962 y disposiciones concordantes, así como el Real Decreto 1504/1984, de 8 de febrero, sobre transferencias a la Comunidad Autónoma de Castilla y León, y el informe de la Asesoría Jurídica General de la Junta de Castilla y León. CONSIDERANDO: Que el Estatuto de Autonomia (L. O. 4/83, de 25 de febrero, art. 27) "En el marco de la legislación básica del Estado y, en su caso, en los términos que la misma establezca, es competencia de la Comunidad de Castilla y León el desarrollo y la ejecución de la legislación del Estado en materia de montes y aprovechamientos forestales". CONSIDERANDO: Que la situación jurídica creada por la sentencia del Tribunal Supremo, supone que estamos a la vista de una nueva tramitación del expediente, donde todavía no se ha dictado resolución, ya que la anulada por el Tribunal Supremo desapareció del mundo jurídico. CONSIDERANDO: Que las facultades y competencias de la Administración en esta materia se limitan a determinar a efectos de su reflejo en el catálogo de montes de utilidad pública, la condición jurídica de las servidumbres y demás derechos reales, conforme establece el articulo 16, segundo, de la Ley de Montes. CONSIDERANDO: Que sin embargo las facultades y competencias antes señaladas no alcanzan ni pueden llegar al extremo de resolver cuestiones relativas a derechos de propiedad y demás derechos civiles, por ser cuestiones cuya competencia resolutoria corresponde en última instancia a los Tribunales ordinarios $y$ en este sentido la discutida existencia o no de la servidumbre y demás derechos alegados para su inclusión en el catálogo, deberán ser precisamente determinadas por aquellos Tribunales, a tenor de lo establecido en el articulo 9 de la Ley de Montes a "ser su contrario". Por todo ello, en virtud de las atribuciones que tengo conferidas. RESUELVO desestimar la reclamación previa planteada por el Ayuntamiento de Orduña (Vizcaya), por versar sobre cuestiones cuya competencia para conocer y decidir corresponde a los Tribunales ordinarios. Valladolid, 22 de enero de 1986. El consejero. Fdo.: Jaime González González.» 
4. La maquinaria administrativa, la puesta a punto de la infraestructura pastoril (cierre de cuevas y portillos, limpieza de pozos de agua...), aspectos que caen dentro de la administración y gestión del monte han sido compartidos y sufragados por ambas entidades tal como queda demostrado en documentación perteneciente a los siglos XVII, XVIII, XIX y XX.

5. La organización y regulación técnico-productivas, que cubren decisiones referentes a las modalidades escogidas para el disfrute de los aprovechamientos y creación y conservación de infraestructura pastoril (subasta de boñigas, de obras de construcción, conservación y limpieza de abrevaderos), al reparto del arbolado, etc., han sido aspectos en los que ambas entidades han intervenido en estrecha colaboración $y$, financieramente, a partes iguales, lo que, documentalmente, consta para los siglos XVII, XVIII, XIX Y XX.

6. En los años cincuenta del siglo $X X$, en contradicción con lo anteriormente relatado, Villalba, Múrita, Mijala y Zaballa, sirviéndose de que Orduña no figuraba específicamente como dueño del monte Dehesa del Agua, y apoyándose en la legislación forestal, negaron cualquier participación al Ayuntamiento de Orduña en Sierra Salvada Baja.

7. La actuación en el asunto, por parte de la Administración forestal, ha sido claramente desafortunada y perjudicial para los intereses de Orduña en tres momentos claves. Uno, el 7 de noviembre de 1955 cuando, conociendo las reservas y oposición de Orduña, no tuvo reparos en expedir licencia de pastos a favor de Villalba por el período de 1955-1960; dos, en noviembre de 1959, al suplir la facultad de audiencia a la que Villalba tenía derecho, siendo motivo del recurso contencioso-administrativo contra la Orden del Ministerio de Agricultura de 7 de julio de 1961, del que, por sentencia del Tribunal Supremo de 11 de junio de 1963, derivó en la anulación, por defecto de forma, de lo hasta entonces tramitado; tres, por la alarmante lentitud con que subsanó errores que solamente a ella competían, iniciando de nuevo la tramitación del expediente promovido por Orduña.

8. En la documentación, la relación de la jurisdicción con el dominio difícilmente puede ser seguida: escasos detalles expresos pueden encontrarse entre la misma. Sin embargo, esa relacion dominio-jurisdicción vuelve a estar presente hasta nuestros días, pues si no cómo puede interpretarse que Villalba discuta los derechos de Orduña porque su nombre no figure en la casilla de pertenencia del monte Dehesa del Agua (número 447 del Catálogo) 
$y$, sin embargo, no tiene inconveniente en aceptar a Múrita, Mijala y Zaballa, que están en su jurisdicción, pero tampoco figuran con sus nombres en el Catálogo.

9. Con el paso del tiempo han ido desapareciendo derechos que las partes disfrutan en la sierra. De los pastos de Oyalarte y Santiago, contemplados en la Carta Ejecutoria de 1494, nada más se conoce. La jurisdicción acumulativa en la Peña de San Bartolomé, con los dos «misteriosos» mojones de jurisdicción privativa, se visitó, por última vez, en los años sesenta del XIX. Villalba, al menos a principios del $X V$, disfrutaba de exención de pago en el peaje de la Peña de San Bartolomé, y en el de la Peña de Goldecho a finales del XVII, pero a mediados del XVIII no consiguió el reconocimiento legal de las mismas.

La relación de fuerzas intercomunitarias, la obsolescencia económica, de derechos sobre bienes y aprovechamientos, los costes económicos de oportunidad, etc., son factores que jugaron en la desaparición-prescripción de los mismos y que pone de manifiesto unas relaciones jurídicas fluctuantes respecto a los bienes y cosas insertas en Sierra Salvada. Si los acontecimientos sucedidos en Sierra Salvada Baja en los últimos cuarenta años corresponden con una etapa de alteración de las relaciones jurídicas derivadas de la posesión y aprovechamiento de la sierra, según se habían caracterizado entre los siglos XV-XX (años cuarenta), es algo que está por ver y que solamente podrá saberse cuando el asunto, sea por inhibición pasiva de Orduña o bien por las correspondientes resoluciones judiciales, quede cerrado.

\section{BIBLIOGRAFIA}

Catálogo de montes y demás terrenos forestales públicos exceptuados de la desamortización por razones de utilidad pública. Provincia de Alava. Vitoria, Imprenta Provincial, 1900.

Catálogo de montes y demás terrenos forestales públicos exceptuados de la desamortización por razones de utilidad pública. Provincia de Burgos ("Gaceta de Madrid" 13, 24, 29 de abril y 31 de mayo de 1901).

Beaglehole. E.: «Propiedad», en Sills D. (Dir.): Enciclopedia Internacional de las Ciencias Sociales. Madrid, Aguilar, 1976, 577-579.

Cadiñanos BardeCl: I., "Villalba de Losa y el castillo de los Duques de Frías", en Angosto, marzo, 1984, 12-13.

garayo Urruela, J. M.: Orduña, siglo XX: demografía, economía y sociedad. Universidad de Deusto. Tesina de licenciatura, 1977. Publicado un resumen en forma de artículo bajo el título de: "Orduña en el siglo XX», en Estudios Vizcainos, núms. 9-10 (1974), 192-253. 
Garcia Sainz de Baranda, J.: "El valle de Losa: notas para su historia», en Boletín de la Institución Fernán González y de la Comisión Provincial de Monumentos Históricos y Artísticos de Burgos, 98 (1947); 301-306, 99 (1947); 387-394, 100 (1947); 462-467, 102 (1948); 57-60, 104 (1948); 169-174, 105 (1948); 270-272, 106 (1949); $51-58$ y 108 (1949); 199-206.

Madaria, J. R.: "Orduña la ciudad del Señorío», en Estudios Vizcainos, 1971, II, 357-363; La ciudad de Orduña. Bilbao. Caja de Ahorros Vizcaína, 1981.

Madoz P.: Diccionario Geográfico Histórico de España y sus posesiones de Ultramar. Madrid, 1849, XII, 301-302.

Nieto. A.: Bienes comunales. Madrid, Editorial Revista de Derecho Privado, 1964.

Orella UnzÚE, J. L.: «Régimen municipal en Vizcaya en los siglos XIII y XIV: El Señorío de la villa de Orduña», en Lurralde, investigación y espacio, 3 (1980), 163-245.

Ortega VAlCÁRCEL. J.: La transformación de un espacio rural. Las montañas de Burgos. Estudio de Geografia Rural. Universidad de Valladolid, Departamento de Geografía, 1974.

Sarasola, M.: La ciudad de Orduña y su vizcainía. Bilbao, 1957.

URIARTE, J. E.: Historia de Nuestra Señora de Orduña la Antigua. Bilbao, Imprenta de la Viuda de Calle, 1883. 